\title{
US fiscal deal leaves science vulnerable
}

\section{Congress delays mandatory cuts to agencies.}

\section{BY HEIDI LEDFORD}

$\mathrm{L}$ aw-makers in Washington DC greeted the new year with a frantic deal meant to avert a fiscal crisis. But the bill that passed the Senate and the House in pre-dawn votes on 1 and 2 January keeps researchers on tenterhooks for at least another two months by delaying mandatory spending cuts that could threaten science funding.

The last-ditch effort aimed to stave off the effects of the 'fiscal cliff': a painful series of tax hikes and budget cuts, scheduled to take effect in 2013, that is meant to reduce the US budget deficit but could push the country's weak economy back into recession. The cuts, known as the sequester, could shrink federal support for research and development (R\&D) by US\$57.5 billion over the next five years.

Rancorous last-minute negotiations yielded a tenuous agreement to raise taxes for the wealthy, but deferred decisions on the sequester - an across-the-board reduction of about $8 \%$ in nondefence discretionary spending,

with at least 9\% carved from defence - by two months. "The bill isn't ideal," says Eleanor Dehoney, vice-president of public policy at Research!America, a science-advocacy group based in Alexandria, Virginia. "But it does give advocates more time to convince policymakers that cutting the US investment in R\&D is counterproductive."

Federal agencies such as the National Institutes of Health (NIH) and the National Science Foundation have not announced what cuts they would make in the event of a sequester, but many institutions have drawn up contingency plans in case there is a sudden plunge in government funding. Nancy Andrews, dean of the Duke University School of Medicine in Durham, North Carolina, says that the medical school may need to cut back on graduate admissions, freeze salaries and

DNATURE.COM Read about Barack Obama's secondterm challenges: go.nature.com/kaaorm reduce faculty recruitments if the NIH takes a severe hit.

The two-month delay to the sequester is a complication for Andrews, who is wrestling with decisions on faculty retention and recruitment that must be made by mid-January. "If we need to spend more to help current faculty members maintain their research programmes through funding gaps, it will be harder to provide start-up funding for new faculty members," she says.

The delay means that law-makers will debate the sequester at the same time as they tackle the overall federal budget. The US Congress's inability to agree on a 2013 budget last year led it to adopt a continuing resolution that allows the government to keep functioning at roughly 2012 funding levels. That resolution expires on 27 March. By then, the country will also have reached a cap on the amount
"The bill isn't ideal. But it does give advocates more time

to convince policy-makers that cutting US investment in R\&D is counterproductive." of money that it can borrow.

This timing may increase the momentum behind big spending cuts, cautions Michael Lubell, director of public affairs for the American Physical Society in Washington DC. But it may also foster a more thorough discussion of which programmes should be cut and by how much, he adds. Science is unlikely to emerge unscarred, says Lubell, but it may end up in better shape than it would have under the original sequestration plan. "That doesn't mean it's going to be wonderful," he adds. "It means it will be less bad." -
OBITUARY

\section{Maxine Clarke (1954-2012)}

\section{Publishing Executive Editor of Nature.}

Cor those of us who were lucky enough to have Maxine as a colleague, it is so difficult to believe that she is no longer with us. She died last month after a battle with cancer that lasted several years. It was a battle fought with great personal courage and resilience, as well as with immense professionalism.

Given the history of her illness, Maxine's death should not have come as much of a surprise. Yet, despite knowing about her challenges, I and her closest colleagues experienced shock and disbelief on hearing that she had passed away. That, in itself, reflects her steadfast refusal to be defined by her illness. She instead maintained her active commitment to Nature and her colleagues - who equally refused to conceive that anything could deprive them of her counsel.

Maxine joined Nature in 1984, under the editorship of John Maddox, having been a researcher in the biophysics of muscle

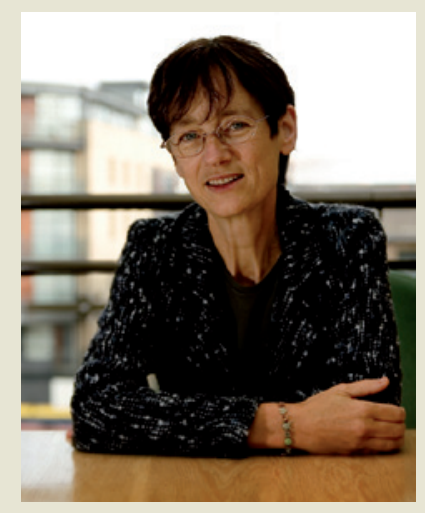

contraction. During her time at Nature, she held a variety of important posts before assuming her final role as Publishing Executive Editor.

Throughout her career she displayed a passionate commitment to Nature, focusing particularly on its scientific standards, its championship of intellectual integrity, the quality of its text, visual presentation, production standards and workflows, and the management of its staff. She never ceased to care and advocate for the working lives of those whom she managed. But, as I know from unsolicited compliments from authors over the years, she was highly valued outside the office too.

As a senior colleague put it: "Maxine was Nature through and through." Having been thankful for her many insights over the years, my colleagues and I will miss her greatly.

Philip Campbell, Editor-in-Chief, Nature. 